\title{
Correspondence
}

\section{Prolonged spontaneous pneumomediastinum in adult dermatomyositis}

SIR, We read with great interest Dr Bradley's first reported case of pneumomediastinum in an adult with dermatomyositis. ${ }^{1}$ We describe here a similar event, where spontaneous pneumomediastinum occurred in a patient with dermatomyositis and persisted for five months.

In January 1986 a 20 year old man was admitted to hospital for assessment of recent generalised muscle' weakness. Examination showed a classic periorbital heliotrope rash, violet oedematous skin lesions over the metacarpophalangeal joints, and numerous vasculitic lesions on the fingers. Proximal muscle weakness was noted and the serum creatine phosphokinase (CPK) was raised at $635 \mathrm{IU} / 1$ (normal 0-186 IU/l). Treatment was started with prednisolone $60 \mathrm{mg} /$ day, and muscle power and CPK levels returned to normal. His cutaneous manifestations persisted, however. He continued to receive high dose prednisolone until July 1986 when he experienced severe pleuritic chest pain lasting several hours. One week later he developed marked surgical emphysema of his neck and anterior chest wall. A chest $x$ ray showed a pneumomediastinum but no pneumothorax, bullae, or interstitial lung disease. Bronchoscopy, oesophagoscopy, Gastrografin swallow, and tests for diabetes were normal. Generalised muscle weakness was noted at this time, and azathioprine was added to his therapy.

On follow up over the next three months the pneumomediastinum and subcutaneous emphysema improved briefly but then increased dramatically again. He was readmitted in October 1986 . Pulmonary function tests showed a forced vital capacity of 2.40 litres, forced expiratory volume of $2 \cdot 25$ litres, peak expiratory flow rate of $365 \mathrm{l} / \mathrm{min}$, and a single breath diffusing capacity $86 \%$ of the predicted value. The pneumomediastinum improved gradually with bed rest and cleared after two months.

Despite the resolution of the pneumomediastinum there was marked systemic disease activity. The patient had intermittent pyrexia with a raised erythrocyte sedimentation rate, marked anaemia, and diffuse muscle weakness. A repeat muscle biopsy confirmed continuing myositis, and treatment was started with high dose prednisolone and cyclophosphamide.

We feel that this case confirms an association between adult dermatomyositis and spontaneous pneumomediastinum and emphasises that the condition can be unusually persistent and troublesome.

St Vincent's Hospital, Dublin

\section{Reference}

1 Bradley J D. Spontaneous pneumomediastinum in adul dermatomyositis. Ann Rheum Dis 1986; 45: 780-2.

\section{Muramidase in the synovium}

SIR, I read with interest the article of Mapp and Revell in the Annals. ${ }^{1}$ It is rather unfortunate that they missed oup article published in 1974, in which we described discovery $V$ and localisation of muramidase (lysozyme) in the humang synovial tissue. ${ }^{2}$ To define the source of muramidase in the synovial fluid we tested cultured synovial tissue for 13 dayక్ and found that muramidase was liberated from the synovial tissue to the medium. Rheumatoid synovial tissue released 5-20 times more muramidase than osteoarthritic or post-traumatic synovial tissue. Subsequently, wर fluoresceinated antihuman lysozyme antibody and found that lysozyme was indeed localised in the cytoplasm of the synovial lining cells and the cytoplasm of polymorphonu: clear and mononuclear cells localised in the synoviab membrane. Lysozyme was found in the specimens thas derived from rheumatoid, osteoarthritic, and post traumatic synovial tissues, but it was much more promi nent in the rheumatoid specimens. The article of Mapp and Revell confirms and expands our original observations

Rheumatic Disease Unit, W PRUZANSKt

University of Toronto,

The Wellesley Hospital

\section{References}

1 Mapp P I, Revell P A. Ultrastructural localisation of muramie dase in the human synovial membrane. Ann Rheum Dis 1987 . 46: 30-7.

2 Pruzanski W, Ogryzlo M A, Katz A. Lysozyme production an ${ }^{\circ}$ abnormalities in rheumatic disease. In: Osserman E F, Canfiel\$ R E, Beychok S, eds. Lysozyme. New York: Academic Press 1974: $419-25$.
E CARMODY

J MCNICHOLL

G CHADWICK

B BRESNIHAN

$X$ FITZGERALD
SIR, We thank Professor Pruzanski for drawing ouf attention to his article, which is of historical interest. The point of our article was not that there is lysozyme in thథ intimal cell layer, but that we are able to localise it to particular organelle in a particular cell type.

Bone and Joint Research Unit,

The London Hospital Medical College, London E1 2AD 